\title{
Synapses Formed by Identified Retinogeniculate Axons during the Segregation of Eye Input
}

\author{
Gregor Campbell and Carla J. Shatz \\ Department of Neurobiology, Stanford University School of Medicine, Stanford, California 94305
}

The synaptic organization of identified retinogeniculate axons was studied during the prenatal development of eyespecific layers in the LGN of the cat. During this period, retinogeniculate axons undergo stereotyped morphological changes. Retinogeniculate axons originating from one eye and passing through LGN territory destined to be solely innervated by the other eye (inappropriate territory) initially give rise to many side branches. As the eye-specific layers emerge, these axons elaborate extensive terminal arbors within territory appropriate to their eye of origin and concurrently retract their side branches from inappropriate territory (Sretavan and Shatz, 1986). These transient side branches may therefore represent a morphological substrate for the observed functional convergence of inputs from the two eyes onto common LQN neurons during prenatal development (Shatz and Kirkwood, 1984). This possibility was investigated by examining whether identified axons and their side branches form synapses in inappropriate territory.

Three retinogeniculate axons from two fetuses aged embryonic day 53 (E53) and E57 were filled with HRP in an in vitro preparation, prior to being processed for electron microscopy (EM). The HRP-filled axons, originating from the contralateral eye, were first reconstructed at the light microscope level. The portion of axon passing through the center of ipsilaterally innervated layer A1 was then serially sectioned and reconstructed by EM. Two sets of $\mathbf{4 5 0}$ serial EM sections revealed that all three contralateral axons established synaptic contacts in ipsilateral territory. Many of these synapses were made by side branches and a few were even formed by the main axon trunks. Both side branches and trunks formed mainly en passant asymmetrical contacts that were associated with spherical synaptic vesicles and that were apposed to immature dendritic elements and dendritic shafts. For comparison, a portion of the same E53 axon within the future contralateral layer $A$ was also serially sectioned and reconstructed for EM. Within this contralateral zone, the E53 axon formed synaptic contacts similar to those

\footnotetext{
Received Aug. 16, 1991; revised Dec. 12, 1991; accepted Dec. 17, 1991.

We thank Drs. R. W. Guillery, A. R. Lieberman, and S. K. McConnell for their comments on the manuscript, Mark Siegel for his assistance with surgery, David Sretavan for help with the in vitro method, and Nicky Campbell and Maria Hernandez for photographic assistance. Thanks also to Jack McMahan for use of the Philips EM400 and to Cecele Thomas for word processing. This work was supported by NIH Grant EY02858, NSF Grant BNS 8616798, and the March of Dimes.

Correspondence should be addressed to Carla J. Shatz, Department of Molecular and Cell Biology, LSA 221, University of California, Berkeley, CA 94720.

Copyright $(\mathcal{C} 1992$ Society for Neuroscience $0270-6474 / 92 / 121847-12 \$ 05.00 / 0$
}

established in the ipsilateral region, except that in the appropriate zone they contained significantly more synaptic vesicles.

These results demonstrate that axons from the contralateral eye can establish synapses in territory simultaneously innervated by the ipsilateral eye, both via side branches and by means of contacts along the main axon trunk. Thus, the development of eye-specific layers is accompanied by the formation and subsequent elimination of synapses that almost certainly represent a morphological substrate for the known transient functional convergence of inputs from the two eyes.

When connections first form during the development of the CNS, frequently they are not as precise as those present in the adult. The adult pattern then emerges during a period in which initially diffuse connections are refined (Purves and Lichtman, 1980). In the mammalian visual system, the rigid segregation of ganglion cell axons from the two eyes into adjacent and separate territories within the adult LGN is achieved by the gradual restriction of initially overlapping eye inputs (for review, see Shatz and Sretavan, 1986). For example, in the cat's visual system, segregation of the retinogeniculate projection into the eye-specific layers occurs during the 3 week period just bcforc birth (gestation is $65 \mathrm{~d}$ ) (Shatz, 1983). Recent studies have shown that the formation of the layers arises as a consequence of a characteristic sequence of changes (summarized in Fig. 1) in the morphology of individual retinal ganglion cell axons (Sretavan and Shatz, 1986, 1987). Prior to the onset of segregation, axons are very simple morphologically, with few branches. When segregation begins, as heralded by the appearance of a small zone exclusively occupied by axons from the ipsilateral eye (Fig. 1, E46, I), axons have acquired a modest terminal arbor and give rise to short side branches that punctuate the axon trunk along its entire course across the LGN. As segregation nears completion by birth and the eye-specific layers become clearly defined, axons have eliminated the many side branches present within territory belonging to the other eye at earlier ages (Fig. 1, E46, E53) and have established elaborate terminal arbors restricted to the territory appropriate to their eye of origin (Fig. 1, E63).

Recent evidence suggests that the prenatal segregation of eye input within the LGN, like similar developmental events known to occur elsewhere in the nervous system (LeVay et al., 1980; Stryker and Harris, 1986; Callaway et al., 1987; for review, see Constantine-Paton et al., 1990; Shatz, 1990a,b), may involve an activity-dependent competitive interaction between the ganglion cell axons from the two eyes for common LGN neurons. For example, prenatal infusions of TTX prevent the formation 
E 46 E53
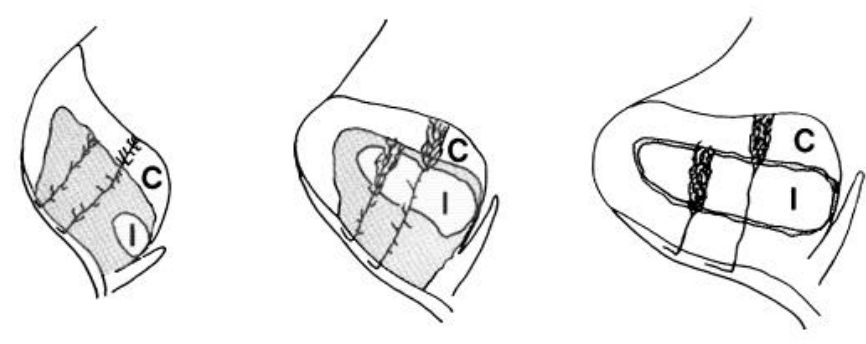

Figure 1. Schematic drawings summarizing the development of two representative retinogeniculate axons between E46 and E63. These axons are superimposed upon drawings of cross sections of the LGN, which reveal those areas innervated by ipsilateral $(I)$ and by contralateral (C) retinal ganglion cell axons; $C$ corresponds to future layer $\mathrm{A}$, while $I$ corresponds to future layer $\mathrm{A} 1$; those areas receiving inputs from both eyes are shaded (based on the pattern of anterograde labeling resulting from intraocular injection of HRP into one eye and ${ }^{3} \mathrm{H}$-leucine into the other). As retinogeniculate axons segregate into eye-specific layers (e.g., as the $C$ and $I$ areas emerge from large regions of shading), axons forming a terminal arbor within contralateral eye territory also give off side branches within ipsilateral eye territory $(E 46, E 53)$. These side branches then disappear by $E 63$ (adapted from Fig. 5 of Shatz and Sretavan, 1986). Note that at E53, clear zones belonging to both contralateral and ipsilateral eyes are already present. (See introduction for further details.)

of the eye-specific layers and the refinement of ganglion cell terminal arbors in the cat (Shatz and Stryker, 1988; Sretavan et al., 1988; Shatz, 1990b). Moreover, in vitro microelectrode recordings from LGN neurons at times when the inputs from the two eyes are intermixed within the LGN, but not later on, indicate that individual postsynaptic neurons receive convergent excitatory inputs from both optic nerves (Shatz and Kirkwood, 1984). Is it not known, however, whether these functional inputs are mediated by direct monosynaptic excitatory inputs from ganglion cell axons themselves, or whether some, particularly those from the inappropriate eye, are mediated by a disynaptic pathway involving LGN neurons.

Previous studies in hamsters have shown that ganglion cell axons from one eye can indeed make synaptic contacts in territory later belonging to the other eye (Campbell et al., 1984). There is no information available that relates these synapses to the overall structure of the ganglion cell axon, however. The location and transient nature of the side branches given off along the length of retinal ganglion cell axons within the LGN suggests that they may be sites of synaptic contact and therefore represent a distinct morphological substrate for monosynaptic physiological interactions. If so, the side branches must be expected to establish transient synaptic contacts with LGN neurons. In order to investigate this possibility, we labeled individual retinogeniculate axons with HRP during the period of segregation in an in vitro preparation and then reconstructed them by electron microscopy (EM). Here we report that axons from the contralateral eye do form transient synapses within ipsilateral eye territory, both by means of the side branches and also via the main axon trunk.

Brief notes of some of these findings have appeared previously (Campbell and Shatz, 1986; Shatz, 1990a; So et al., 1990).

\section{Materials and Methods}

Two fetuses aged embryonic day 53 and 57 (E53 and E57) were used for the present study. Timed pregnancies allowed us to select the fetal age within $\pm 24 \mathrm{hr}$ (see Shatz, 1983).
Surgery. Sterile surgical technique was used for all procedures. Pregnant cats received subcutaneous injections of atropine sulfate $(0.05 \mathrm{mg} /$ $\mathrm{kg})$ and intramuscular injections of ketamine hydrochloride $(20 \mathrm{mg} / \mathrm{kg})$ and acepromazine $(0.2 \mathrm{mg} / \mathrm{kg})$. Anesthesia during surgery was maintained with a mixture of halothane $(0.5$ to $1.5 \%)$ and oxygen via an endotracheal tube. Full details of fetal surgery are given in Shatz (1983) and Ramoa et al. (1988).

In vitro preparation. This electron microscope (EM) study of the retinogeniculate axons in prenatal cats was carried out using an in vitro preparation similar to that used by Sretavan and Shatz (1986). Fetuses were removed by cesarean section and placed on ice. The brain was quickly exposed and the diencephalon bisected along the midline; one half was placed in a modified tissue slice chamber, where it was continuously superfused with oxygenated Ringer's solution $\left(32-34^{\circ} \mathrm{C}\right)$ at a rate of $80-100 \mathrm{ml} / \mathrm{hr}$ (Shatz and Kirkwood, 1984). The other half was pinned to a Sylgard-coated Petri dish medial side down, and two to three horseradish peroxidase-coated micropipette tips were inserted into the optic tract just ventral to the LGN and anterior to the medial geniculate nucleus. A $2-3 \mathrm{~mm}$ horizontal slice including the injection sites and the ventral three-quarters of the LGN was then cut with a razor blade and immediately placed in the slice chamber. Since the most satisfactorily filled axons were about $1.5 \mathrm{~mm}$ from the injection sites, the dorsalmost portion of the LGN was also removed to bring the remaining slice of LGN closer to the superfusion fluid, thus avoiding necrosis in this region. The same HRP procedure was then carried out with the other half of the LGN preparation.

HRP processing. After $3 \mathrm{hr}$ in the chamber, the slices containing the lateral geniculate nuclei were immersed in fixative ( $1 \%$ paraformaldehyde and $1.25 \%$ glutaraldehyde in $0.1 \mathrm{M}$ sodium phosphate buffer with $0.5 \%$ glucose) and left at $4^{\circ} \mathrm{C}$ for about $20 \mathrm{hr}$. The slices were embedded in gelatin-albumin, and $100 \mu \mathrm{m}$ horizontal sections were cut on a Vibratome and collected in cold phosphate buffer. The HRP reaction product was revealed by reacting sections with diaminobenzidine (DAB) $(0.05 \%)$, cobalt chloride $(0.025 \%)$, and hydrogen peroxide using $0.1 \mathrm{M}$ sodium cacodylate buffer ( $\mathrm{pH} 7.3$ ). The E57 material was processed with $\mathrm{DAB}$ but with a higher concentration of cobalt chloride $(0.56 \%)$ together with ammonium nickel sulfate $(0.37 \%)$.

Electron microscopy. Sections judged to contain good HRP-filled axons were pinned to Sylgard-coated Petri dishes, osmicated $(2 \%$ in 0.1 M sodium phosphate buffer for $1 \mathrm{hr}$ ), stained in aqueous uranyl acetate $\left(2 \%\right.$ at $4^{\circ} \mathrm{C}$ for $\left.1 \mathrm{hr}\right)$, dehydrated in a graded series of ethanols, cleared in propylene oxide, and embedded in Epon-Araldite.

The resin embedded sections were examined with a light microscope (LM). Three axons well labeled with HRP (1 at E53, 2 at E57) from two blocks formed the basis of this study. They were all typical of retinogeniculate axons at E53 and E57 (see Sretavan and Shatz, 1986). Each could be traced from close to the optic tract through the LGN in a short series of adjacent resin sections (see Figs. $2 a$; 16, inset). We approached the axon of interest during the cutting of $1 \mu \mathrm{m}$ sections by using camera lucida drawings (see, e.g., Figs. $2 b, 16)$ and measurements of axon depth within the block. This also allowed us to distinguish the axon of interest from the few nearby HRP-labeled axons. Ultrathin serial sections were collected on Formvar-coated, single slot grids. Approximately 450 serial sections were cut from each block. These were counterstained with lead citrate and viewed in Philips EM201 and EM400 electron microscopes.

There were many problems associated with trying to obtain axons that were well filled and also suitable for EM study. For example, when viewing HRP-labeled profiles in a particular EM section, it was important to be sure that they belonged to the axon of interest so that time was not wasted in reconstructing neighboring axons. The chosen labeled axon therefore had to be in a region of a resin section fairly well isolated from other labeled axons. In addition, to be sure we were studying contralaterally projecting retinogeniculate axons, the filled axons had to arise from close to the optic tract and terminate in an immature arbor at the inner LGN border (see Results, General observations). Further conditions for the suitability of an axon for EM study were the necessity for that area of the LGN to be non-necrotic and well fixed. Only 2 out of 10 fetuses yielded axons that met all of these criteria.

Analysis. Serial EM sections were systematically viewed and any HRPlabeled profiles photographed at a range of magnifications. Care was taken to differentiate between those elements that contained HRP reaction product and those profiles that appeared to represent degenerating processes. In all the reconstructed axons, reaction product of a fairly uniform electron density was seen throughout the axon trunk and side branches. That is, a labeled portion of axon was never traced into 
continuity with an unlabeled segment of axon. Photographic montages at low magnification $(300-600 \times)$ of about every fiftieth serial section were made to enable the accurate mapping of HRP-labeled profiles with respect to landmarks such as blood vessels and section boundaries. Portions of the three axons (100-200 $\mu \mathrm{m}$ lengths) were reconstructed from electron micrographs at $25,000 \times$ final magnification. Every labeled profile on these micrographs was drawn on tracing paper and the tracings aligned as accurately as possible through the entire series of sections by using several additional traced structures in each micrograph as reference points (see Gaunt, 1971). In this way large, traced reconstructions of the axons were obtained in two dimensions.

Quantitative data. Counts were made of the number of synaptic vesicles and measurements were made of the length and width of the postsynaptic densities at every synapse. For several reasons, counts were made of synaptic vesicles apposed to a clear postsynaptic density only in the single section that contained the maximum number. First, we did not have a complete series of sections through every synapse. In addition, synapses were often made en passant or were not clearly associated with a terminal swelling or bouton at these very early ages, thereby making it impossible to obtain an accurate measurement of presynaptic volume or vesicle density. Similarly, the length and width of postsynaptic densities were measured in the section of their maximum extent. However, the serial sections available allowed us to determine that we were making a fair assessment of vesicle number per synapse and extent of the synaptic zone.

Autoradiographic labeling of ipsilateral eye territory. In this study, we were interested primarily in those regions of contralaterally projecting retinogeniculate axons that are within LGN territory destined to be solely innervated by the ipsilateral eye. It was quite possible to determine the center of such ipsilateral territory at E57 because at this age segregation of retinogeniculate inputs is almost complete and little overlap remains between ipsilateral and contralateral eye inputs (see Shatz, 1983). This is not the case in the E53 fetus, where there is still extensive intermixing of ganglion cell axons from the two eyes within future ipsilaterally innervated layer A1 (Shatz, 1983). Therefore, to identify unambiguously the region of the LGN innervated by ipsilateral eye axons at E53, we made an intravitreal injection of $500 \mu \mathrm{Ci}{ }^{3} \mathrm{H}$-leucine (TRK 170, Amersham; $49 \mathrm{Ci} / \mathrm{mmol}$ ) in $10 \mu \mathrm{l}$ of $0.9 \%$ saline into the E53 fetus in utero $24 \mathrm{hr}$ prior to the in vitro experiment (see Sretavan and Shatz, 1986, for further details).

To visualize the autoradiographic record of the anterogradely transported tracer, several $1 \mu \mathrm{m}$ semithin sections were cut from a region of the EM resin blocks close to the HRP-filled axon and dried onto subbed slides. These were then dipped in Kodak NTB-2 emulsion, exposed for 6 weeks, and developed in D19. Figure $2 d$ shows a dark-field photomicrograph of one of the resulting autoradiographs. The distribution of ipsilateral retinogeniculate label in this material was verified by, and proved to be very similar to, that using a second autoradiographic method: nonosmicated, Vibratome sections from the same brain slice that yielded the axon under study were rehydrated and placed in contact with a sheet of tritium-sensitive film (Hyperfilm- ${ }^{3} \mathrm{H}$, Amersham) in a light-tight $\mathrm{x}$-ray film cassette for $7 \mathrm{~d}$ and then developed in D-19 (Sretavan and Shatz, 1986). To obtain an accurate assessment of the distribution of radioactive label associated with axons from the ipsilateral eye within the transition region between future layers $\Lambda$ and $\Lambda 1$ at E53 (Fig. 1, E53, shaded region between "C" and "I"), counts of the silver grains were made from a photograph of the original autoradiograph at a magnification of $290 \times$ (Fig. $2 d$ ). The photograph was placed under transparent graph paper, and grains were counted within $0.5 \mathrm{inch}^{2}$ boxes each of which was made up of smaller boxes 0.1 inch $^{2}$, which helped avoid counting the same grains twice. Grains were too densely clumped at the lower end of the autoradiograph (approximately the area below the dotted line in Fig. $2 c$ ) to be counted.

\section{Results}

\section{General observations}

The main goal of the present study was to investigate the ultrastructural features of specific portions of developing retinogeniculate axons. We were particularly interested in those regions belonging to an axon originating from one eye, which passed through LGN territory that in the adult is exclusively innervated by axons of the other eye. Contralaterally projecting axons were selected for study because these can be identified with confidence at older ages even when labeled from the optic tract rather than their nerve of origin. Anterograde tracing studies following intraocular injections have shown that the innermost region of the LGN, which corresponds in the adult to the upper half of layer $\mathrm{A}$, receives an exclusive projection from axons originating from the contralateral eye throughout development (Shatz, 1983). Therefore, as we have argued elsewhere (Sretavan and Shatz, 1986), any axon that arises from the optic tract traverses the entire LGN and terminates at its extreme innermost border, originates from the contralateral eye. This is especially likely by E53 and E57, the ages selected here for study, because the eyespecific layers are well on their way to being formed and, accordingly, the majority of HRP-filled axons have a clearly defined terminal arbor already located within territory that can be unambiguously related to the contralateral or ipsilateral eyes based on the pattern of anterogradely transported label following an eye injection (see Fig. 1; see also Sretavan and Shatz, 1986). Thus, we considered an axon to originate in the contralateral eye if (1) it traversed entirely across the LGN and (2) as described below, it had a clear terminal arbor located outside territory defined as ipsilaterally innervated based on the autoradiographic labeling pattern following an intraocular injection of ${ }^{3} \mathrm{H}$-leucine (see also Sretavan and Shatz, 1986, their Fig. 14A).

The next section of the Results is in two parts. The first part covers a thorough analysis of one HRP-filled retinogeniculate axon at E53 as it passes through both ipsilateral and contralateral eye territory. The second part deals, in less detail, with two HRP-labeled retinogeniculate axons at E57. We chose the ages E53 and E57 for a number of reasons. As mentioned below, segregation of retinogeniculate axons according to eye of origin is virtually complete by E57. This means that, at this age, the LGN has a very distinct ipsilateral eye layer, making it relatively easy to estimate which parts of contralaterally projecting axons lie within ipsilateral eye territory. Unfortunately, contralateral axons at E57 give rise to only a few side branches as the axons course through well defined ipsilateral eyc territory. [At later ages, e.g., at E63, such axons have virtually no side branches (see Fig. 1).] On the other hand, at E53, the number of side branches present along the course of retinal ganglion cell axons within the LGN is close to maximum (Sretavan and Shatz, 1986).

\section{Analysis of E53 axon}

Light microscopy. This axon was drawn and reconstructed from three consecutive Vibratome sections as it passed from the region of deep optic tract fibers (lying about $100 \mu \mathrm{m}$ from the main optic tract) all the way to the inner border of the nucleus (Fig. 2a). It had an immature terminal arbor made up of a number of branches lying well within the inner third of the nucleus identifying it, as explained above, as an axon derived from the contralateral eye. A number of side branches were given off along the axon's length (Fig. $2 b, c$ ). Some of these side branches lay in territory simultaneously occupied by axon terminals from the ipsilateral eye: the location of ipsilateral eye territory was ascertained directly by injecting the ipsilateral eye with ${ }^{3} \mathrm{H}$-leucine and examining the pattern of autoradiographic labeling within the LGN. Figure $2 d$ is such an autoradiograph made from a $1 \mu \mathrm{m}$ semithin section taken from the same block at a level about $25 \mu \mathrm{m}$ above the most superficial, reconstructed part of the axon. Counts of silver grains reveal that the average density of labeling within the stippled area in Figure $2 c$ is $100 \%$ greater than that in the clear area above (an average of $\geq 155$ 
$2 a$
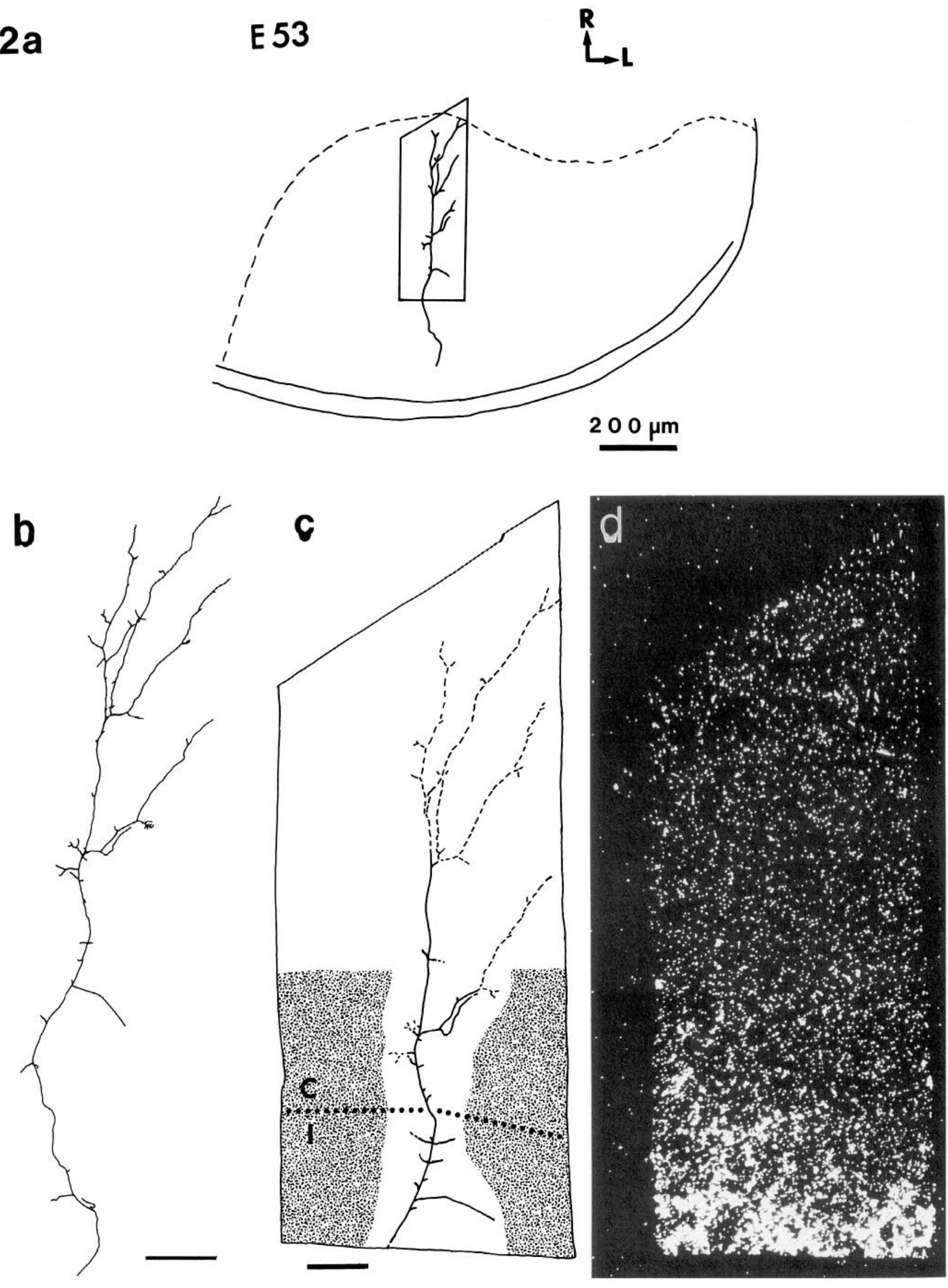
grains 0.5 inch $^{-2}$ vs. $\leq 76$ grains 0.5 inch $^{-2}$ ). Thus, the stippled area definitely receives ipsilateral eye input and represents most if not all of the upper portion of the ipsilaterally innervated LGN at this agc (sec Shatz, 1983, her Fig. 13; Sretavan and Shatz, 1986, their Figs. 13, 14A). Moreover, the stippled area below the dotted line in Figure $2 c$ has a labeling density $140 \%$ greater than that in the nonstippled region ( $\geq 180$ grains 0.5 inch $^{-2}$ vs. $\leq 76$ grains 0.5 inch $^{-2}$ ). Since by E53 this high-density zone of ipsilateral labeling is close to, if not coincident with, the center of ipsilaterally innervated territory, we consider it highly likely that it will become solely innervated by the ipsilateral eye by adulthood. Consequently, we have designated this zone "I" in Figure $2 c$. On the other hand, the stippled zone above the dotted line in Figure $2 c$ ("C") may become exclusively contralaterally innervated by adulthood because it is located at the border region, where it is not possible to predict accurately the final disposition of contralateral versus ipsilateral inputs. Thus, we have conservatively restricted our analysis of "side branches in ipsilateral territory" to those branches located deep within the ipsilaterally innervated region (e.g., below the dotted line of Fig. $2 c$ ).

Electron microscopy. The axon gave rise to numerous side branches. A side branch is defined as a protrusion over $1 \mu \mathrm{m}$ long that arises from the axon trunk. Although many side branches were reconstructed in their entirety (solid lines in Fig. $2 c$ ), not all were (dotted lines in Fig. $2 c$ ). Side branches contained few organelles: most common were small elements of smooth endoplasmic reticulum; less common, except in the larger side branches, were mitochondria, microtubules, and neurofilaments.

Side branches were frequently found to form synaptic contacts, some of which were rudimentary (in ipsilateral territory), whereas others were quite robust. In conformity both with the established criteria for synapses in the adult animal (Peters et al., 1976) and with previous studies of synaptogenesis in the mammalian CNS (Vaughn and Sims, 1978; Blue and Parnavelas, 1983; Vaughn, 1989), we have defined synapses as those structures having at least one vesicle of $40-50 \mathrm{~nm}$ in diameter located close to the presynaptic plasmalemma (a maximum of one vesicle distant), apposed to a postsynaptic membrane associated with distinct electron-dense material. (Note that serial sections often revealed that the presynaptic profile contained many more than one synaptic vesicle.) The opposing presynaptic and postsynaptic membranes are generally parallel, and dense material is present in the synaptic cleft.
Examples of rudimentary synapses formed by two side branches in ipsilateral eye territory at E53 are shown in Figures 3-5. In Figure $3 a$, the section is through a synapse formed close to the tip of side branch 1 of the E53 axon. (For numbering of the side branches and a summary for all contacts, see Fig. 15.) The side branch contains at least two synaptic vesicles closely apposed to the presynaptic membrane; these can be seen more clearly, along with the synaptic cleft, in Figure $3 b$, a tilted view of the same section. The postsynaptic density is evident in both views. Figures $4 a-c$ contains a set of serial sections illustrating an en passant synapse on side branch 2 of the same axon. Again, only one or two synaptic vesicles are present in each section. In Figure $4 b$, a larger vesicle is also present; these have been described as a common feature of rudimentary synapses by Vaughn (1989). Figure 5 shows another example of an en passant side branch synapse that again is very simple, containing only one (Fig. 5a,c) or two (Fig. 5b) synaptic vesicles; a larger vesicle is also present in Figure $5 c$. There is a delicate but distinct postsynaptic density in each case. Figure 6 illustrates two en passant synapses located close to the main axon trunk on sidebranch 3. Both postsynaptic densities are clear in each serial section, but the synaptic vesicles are obvious only in Figure $6 b$. In these respects, the fetal retinogeniculate axonal side branches resemble the irregularly contoured fingerlike processes and filopodia of the early postnatal cat retinogeniculate axons, which also give rise to many en passant synapses (Mason, 1982). Thus, these synaptic contacts are very immature and do not resemble the bouton terminaux or varicosities associated with mature synaptic profiles (Guillery, 1969, 1971; Robson and Mason, 1979).

Because of the HRP reaction product, the presence of presynaptic thickenings could not be used as a criterion for defining synapses. Occasionally, the HRP reaction product also obscured synaptic vesicles. These cases, despite the presence of a definite postsynaptic density, were not categorized as synapses but rather were called "unidentified contacts." An example of such a contact established by the axon in contralateral territory can be seen in Figure $12 c$ (open triangle).

In addition to the side branches, synapses were also found along the main axon trunk. In most respects, these synapses are similar to the side branch synapses in their simplicity. As shown in Figure 7, $a$ and $b$, the trunk of the E53 axon makes a synapse in ipsilateral territory that contains two to four vesicles per section; dense material within the synaptic cleft is also evident, particularly in Figure $7 b$.

Adherens contacts were also present on both side branches

\footnotetext{
Figure 2. Drawings of an E53 retinogeniculate axon that was labeled with HRP in vitro, serially sectioned, and partially reconstructed by EM to reveal its synaptic connectivity as shown in Figures 3-15. $a$ and $b$, Camera lucida drawings of the axon reconstructed from three serial Vibratomc sections. The boxed area delimits that portion of the axon serially sectioned for EM (see $c$ ). The axon arises from close to the optic tract (bottom of $a$ ) and forms a terminal arbor near the inner border of the nucleus (dashed line). Note that the axon is likely to be more complex than can be rcvealcd in this osmicated section. $c$, Drawing of the portion of axon reconstructed by EM in its exact position within the EM block as determined by overlaying the camera lucida drawing of the entire axon taken from $b$ with the outline of the EM block. The camera lucida drawing itself was also matched precisely with those portions of the HRP-labeled axon visible in the osmicated block. Additional side branches revealed by EM have been added to this drawing (compare with $b$ ). Solid lines represent those parts of the axon serially sectioned and reconstructed for EM; dashed lines represent those parts of the axon not studied for EM. The length of some side branches has been exaggerated for clarity. The stippled area represents those regions in which the density of autoradiographic labeling $(d)$ is $50 \%$ or greater than that in the unshaded region above. This stippled area therefore receives substantial input from the ipsilateral eye. It is further subdivided by the dotted line that separates the area receiving very high density of ipsilateral eye input $(I)$ close to the center of the layer from territory receiving lower-density ipsilateral eye input. Since this area of lowerdensity input is also likely to receive high-density contralateral eye input at this age, this region is considered to belong to the contralateral $(C)$ eye (see Results for more details). $d$, Dark-field photomicrograph illustrating an autoradiograph of a $1 \mu \mathrm{m}$ semithin section of the block shown in $a$ and $c$ to show the distribution of anterogradely transported ${ }^{3} \mathrm{H}$-leucine following injection of the tracer into the ipsilateral eye. Note that the main terminal arbor of the HRP-labeled axon extends to the innermost border of the LGN and is located well beyond the zone of dense autoradiographic labeling, indicating its likely origin from the contralateral eye. $R$, Rostral; $L$, lateral. Scale bars: $b$ and $c, 50 \mu \mathrm{m} ; d$ is same magnification as $c$.
} 

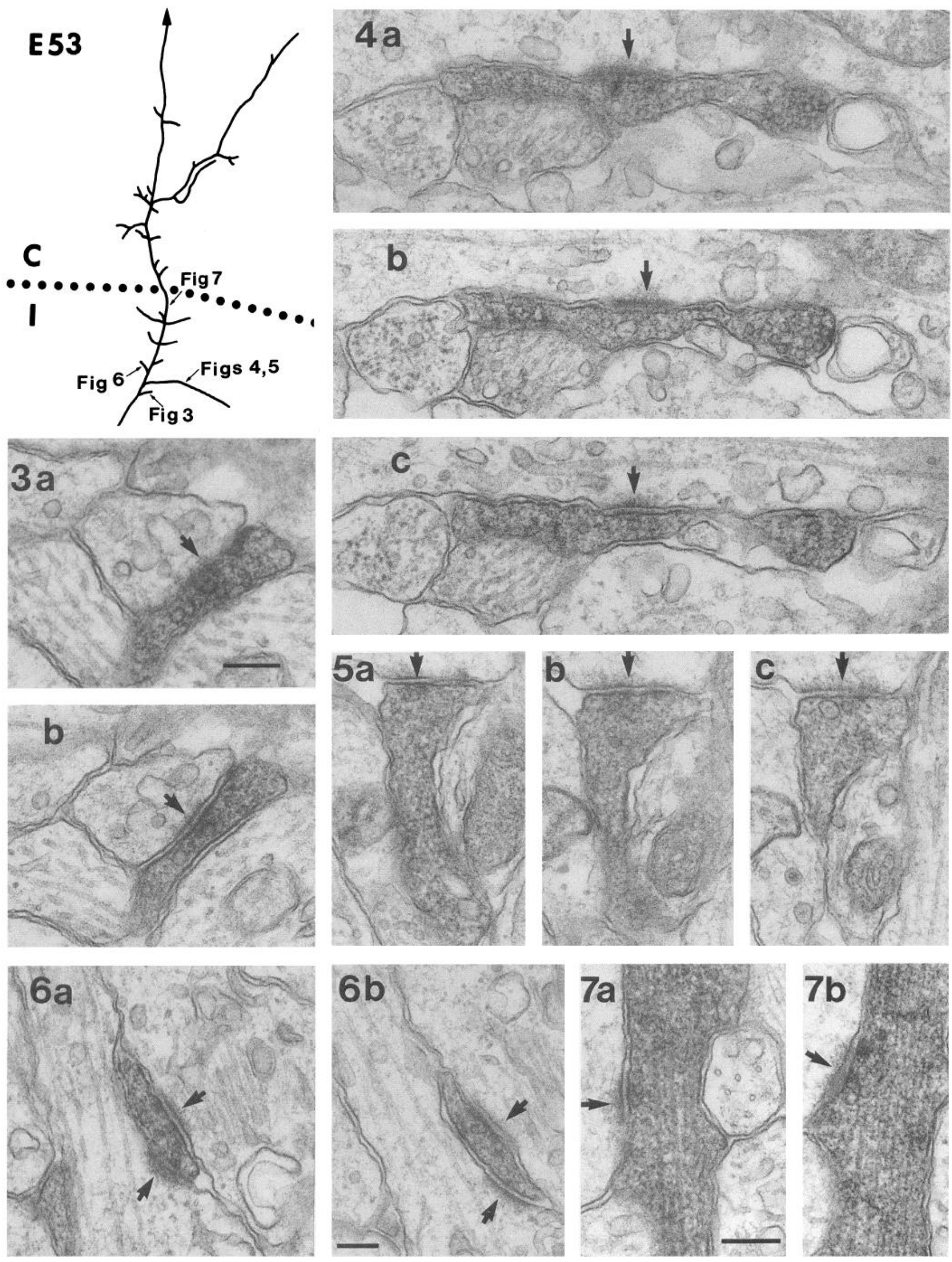
and the trunk and are defined as those contacts having a postsynaptic-like density that was apposed to an area of the axon without any indication of synaptic vesicles (data not shown).

A variety of postsynaptic structures were associated with these synapses. Small to medium size dendritic shafts were sometimes postsynaptic, but more common were elements presumed to be immature dendritic spines or dendritic growth cones on the basis of their similarity to structures described as such in previous studies (Hinds and Hinds, 1972; Skoff and Hamburger, 1974; Vaughn et al., 1974; Westrum et al., 1980; Steward and Falk, 1985). Since we found it difficult to distinguish reliably between these structures, they are not described further here.

The axon in ipsilateral eye territory (Figs. 3-7, Table 1). This portion of axon gave rise to 4 synapses established by the trunk, 10 synapses made by side branches, 3 unidentified contacts, and 4 adherens contacts (for summary, see Fig. 15). At this early age, fully 3 weeks before eye opening, synapses $(n=14)$ have a mean number of 2.8 vesicles (see Table 1 ). The mean postsynaptic density length is $225.6 \mathrm{~nm}$, and the mean postsynaptic density width is $33.0 \mathrm{~nm}$. There were significantly fewer $(p=$ 0.001 , two-tailed $t$ test) vesicles per synapse in ipsilateral eye territory than that in contralateral territory (see Table 1 and compare Figs. 3-5 with Figs. 9-12). However, there was no difference in these parameters between trunk and side branch synapses. There was also no significant difference between the postsynaptic density measurements for synapses in the ipsilateral zone and those for synapses in contralateral territory.

The tips of the side branches in ipsilateral territory were small and blunt and revealed no special ultrastructural features (compare this with the membrane specializations associated with the tips of side branches 9 and 18 in contralateral territory; see Figs. $13,15)$. Several side branches gave rise along their length to small blunt protrusions of about $0.5-1 \mu \mathrm{m}$ in length with no membrane specializations (not illustrated).

The density of synaptic contacts formed by side branches was variable (see Fig. 15). Three side branches $(4,6$, and 8 ) were not presynaptic at all; these were all short $(1-2 \mu \mathrm{m})$. Of the other side branches, three $(1,3$, and 5$)$ were also short $(1.5-5 \mu \mathrm{m})$ but gave rise to one, two, and two synapses, respectively. The two longest side branches (side branch $2,60 \mu \mathrm{m}$, and side branch 7 , $>16 \mu \mathrm{m}$ ) established two or three synapses, and these were clustered over a distance of 2-3.5 $\mu \mathrm{m}$.

The axon in contralateral eye territory (Figs. 8-14, Table 1). This portion of axon formed 3 trunk synapses, 22 terminal arbor synapses, 7 unidentified contacts, and 2 adherens contacts (for summary, see Fig. 15$)$. Synapses $(n=25)$ have a mean number of 7.6 vesicles. The mean postsynaptic density length is 263.6 $\mathrm{nm}$, and the mean postsynaptic density width is $33.6 \mathrm{~nm}$ (see Table 1). There was no difference in these parameters between trunk and side branch synapses. The postsynaptic elements, as for the axon in ipsilateral eye territory, were small to medium sice dendrites and immature dendritic elements.
Table 1. Analysis of synapses made by E53 axon

\begin{tabular}{lllll} 
Territory & $n$ & $\begin{array}{l}\text { No. of } \\
\text { vesicles }\end{array}$ & PSD length & PSD width \\
\hline Ipsilateral & 14 & 2.8 & $225.6 \mathrm{~nm}$ & $33.0 \mathrm{~nm}$ \\
& & $\mathrm{SD}=1.2$ & $\mathrm{SD}=54.3$ & $\mathrm{SD}=10.7$ \\
& & $\mathrm{SEM}=0.3$ & $\mathrm{SEM}=13.6$ & $\mathrm{SEM}=2.7$ \\
Contralateral & 25 & $7.6^{*}$ & $263.6 \mathrm{~nm}$ & $33.6 \mathrm{~nm}$ \\
& & $\mathrm{SD}=4.6$ & $\mathrm{SD}=134.9$ & $\mathrm{SD}=16.1$ \\
& & $\mathrm{SEM}=0.9$ & $\mathrm{SEM}=27.0$ & $\mathrm{SEM}=3.2$ \\
\hline
\end{tabular}

PSD, postsynaptic density.

*, Significantly different from number of vesicles in ipsilateral territory $(p=0.001$, two-tailed $t$ test).

Eleven side branches arose from this section of the axon. All of these are considered to form part of the terminal arbor of the axon by virtue of position with respect to the main branches of the axon and also their location within contralaterally innervated territory as described above. Reconstruction of part of side branch 12 together with selected contacts can be seen in Figure 8 . Side branches $9,11,13$, and 18 were reconstructed in their entirety (see Fig. 2c). Side branches 9, 10, 12, 14, 15, 17, and 18 established one or more synapses (Fig. 15) with immature dendritic profiles (Figs. 11,12b), small to medium size dendrites (Fig. 12a,c), and occasionally larger, proximal dendrites. The density of contacts established by side branches was not uniform, although short (1.5-3.0 $\mu \mathrm{m}$ ) side branches (or short lengths of side branches when they wcre not traced to their tips) usually formed one to three contacts. Two side branches were considerably longer. Side branch 12 had many synapses (seven in 8 $\mu \mathrm{m}$; see Fig. $8 a$, arrows), whereas side branch 15 had fewer (nine in $80 \mu \mathrm{m}$; Fig. 15).

The tips of two of the side branches, 9 and 18, formed specialized associations with immature dendritic processes (side branch 9, not shown) and an unusually narrow dendritic process arising directly from a dendritic shaft (side branch 18; Fig. 13). The tip of side branch 18 contained two round synaptic vesicles that were apposed, across a cleft, to a small membrane density within a narrow $(0.2 \mu \mathrm{m}$ in diameter) dendritic process (Fig. 13). If this latter contact is synaptic, it has an extremely narrow postsynaptic density - the thickness of a single EM section $(\sim 70$ $\mathrm{nm})$ ! Because the synaptic nature of these membrane specializations was equivocal, we included them in our category of unidentifiable contacts. A trunk synapse close to side branch 18 is shown in Figure 14.

\section{Analysis of E57 axons}

Two axons at this age were reconstructed from a single Vibratome section (see Fig. 16, inset). At this age, the eye-specific layers are almost completely formed, and clear ipsilateral and contralateral eye territories are present (Shatz, 1983). Axon A

Figure 3-7. E53 axon: synapses located within ipsilateral eye territory-selected micrographs of serial EM sections from a portion of the reconstructed E53 axon that is located in ipsilateral eye territory and gives rise to side branches 1-8 (see Fig. 15 for numbering of side branches). In this collection of figures (as in Figs. 8-14), the top left corner contains a drawing of that portion of the E53 axon reconstructed for EM. Arrows indicate parts of the axon illustrated here in electron micrographs (Figs. 3-14) and in drawings of serial sections (Fig. 8a). Figure 3, Electron micrographs (one of a tilted section, $b$ ) of the terminal region of side branch 1 containing a few round synaptic vesicles apposed to a postsynaptic density (arrows) within a small dendritic element. Note the electron-dense HRP reaction product within the side branch. Figures 4 and 5 , Two synaptic contacts (arrows) established by side branch 2 are illustrated in two sets ( $4 a-c$ and $5 a-c)$ of three serial sections. Figure 6, Side branch 3 gives rise to two synaptic contacts (arrows) seen here in two serial electron micrographs $(a, b)$. Figure 7 , Two serial sections $(a, b)$ of the same trunk synapse $($ arrows). Scale bars: for Figs. 3-5, shown in Fig. 3a, $0.2 \mu \mathrm{m}$; Fig. 6, $0.5 \mu \mathrm{m}$; Fig. 7, $0.2 \mu \mathrm{m}$. 

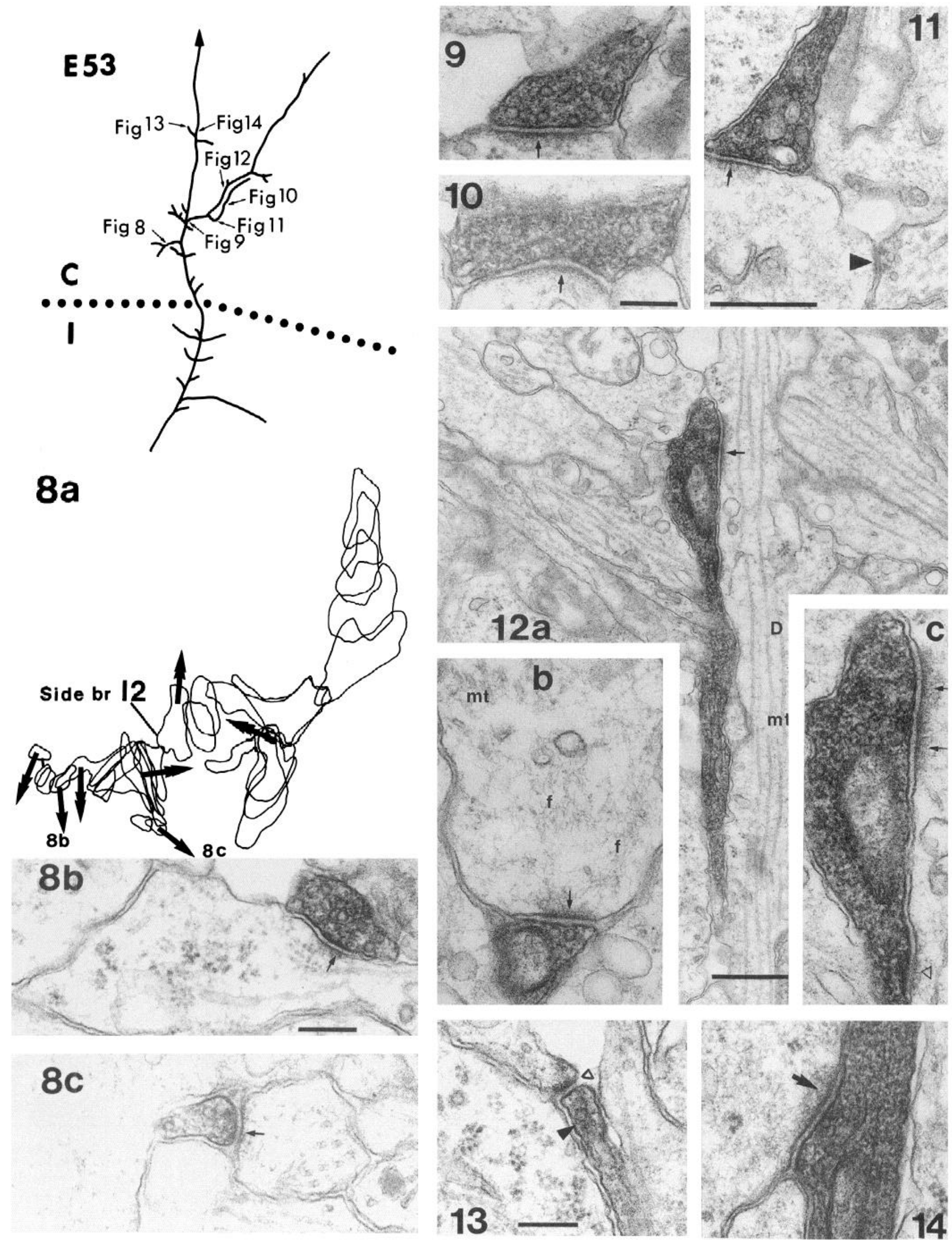
was traced from a position about $150 \mu \mathrm{m}$ from the optic tract to a terminal arbor close to the inner border of the nucleus, indicating that it is derived from the contralateral eye. As it passed through ipsilateral territory it gave rise to five synapses, two from the two side branches present and three from the axon trunk (Fig. 16). The presynaptic density was not visible within the axon due to high electron density of the HRP reaction product. Nevertheless, round synaptic vesicles were clearly visible and abundant within the presynaptic profiles (not illustrated). The postsynaptic target varied in nature: side branch 1 synapsed with a small dendritic element, those associated with the trunk synapses were medium-sized dendrites, and side branch 2 established a synapse with an invaginating dendritic process. Axon $\mathrm{B}$, traced at about $50 \mu \mathrm{m}$ from the optic tract, was of similar basic structure to axon $A$ and also terminated close to the inner border of layer A. The portion of axon B located within ipsilateral territory established three synapses from the trunk (see Fig. 16). All synapses were associated with round vesicles and a thick postsynaptic density located within dendrites of small to medium diameter. One synapse was particularly interesting. It was located at the branch point of side branch 1 within a broadened region of the axon trunk that resembled a web at the LM level (Fig. 16, see also Sretavan and Shatz, 1984). By EM, its true nature was revealed as a thin, broad sheet approximately $1.0 \times 2.0 \mu \mathrm{m}$ and $0.3 \mu \mathrm{m}$ thick that linked two thickened ridges of the trunk. One thickened region gave rise to the long, narrow side branch 1; the other thickened ridge established synaptic contact with a dendritic shaft that was partially enwrapped by the "web" (not illustrated). Similar wrapping of dendritic processes by axons has been seen in other developing systems (Vaughn and Sims, 1978; Bastiani and Goodman, 1984; Bhide et al., 1988; Tosney and Landmesser, 1985) and implies the presence of ongoing and extensive cellular interactions.

\section{Discussion}

By examining the ultrastructural appearance of individually identified retinogeniculate axons at E53 and E57, we have shown that some ganglion cell axons from the contralateral eye not only establish synapses within LGN territory entirely devoted to the representation of their own eye, but can simultaneously make synaptic contacts in ipsilateral eye territory during the formation of the eye-specific layers within the cat's LGN. These results are summarized in Figures 15 and 16, which show the location of synapses made by the three axons subjected to ultrastructural analysis. All three axons demonstrate that contra-
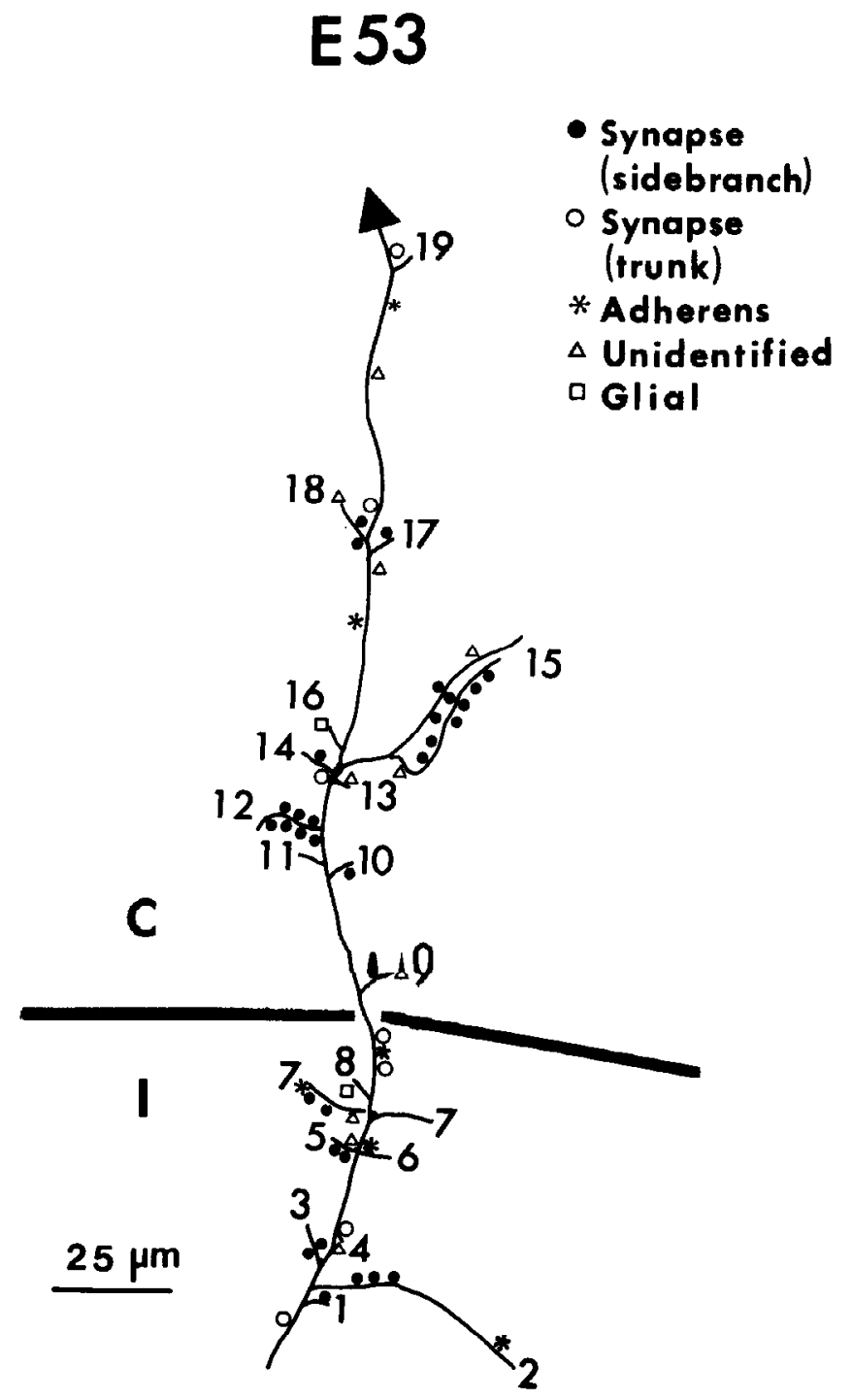

Figure 15. Summary drawing of the contacts made by the axon trunk and side branches (numbered) of the portion of the E53 axon reconstructed from serial EM sections. Twenty-two contacts are established by this contralateral eye axon as it passes through LGN territory innervated by the ipsilateral eye $(I) ; 35$ contacts are made in contralateral eye territory $(C)$. Two contacts made by side branches 8 and 16 with putative glial cells not mentioned in the Results are shown here (squares). Symbols: solid circles, side branch synapses; open circles, trunk synapses; ", adherens contacts; open triangles, unidentified contacts; open squares, glial cell contacts.

Figures 8-14. E53 axon: synapses located within contralateral eye territory-synapses established by side branches 12 (Fig. 8), 14 (Fig. 9), 15 (Figs. 10-12), and 18 (Fig. 13) and a trunk synapse (Fig. 14) of the E53 axon located in LGN territory belonging to the contralateral eye. Figure 8 . Tracings of serial sections $(a)$ and electron micrographs $(b, c)$ of side branch 12 . As this side branch leaves the axon trunk (which is shown at the right side of $a$ ), it follows a twisted course and establishes seven synaptic contacts (arrows; synapses at double arrows are not illustrated). Two of these synapses (arrows $b$ and $c$ ) are illustrated in the corresponding electron micrographs ( $b$ and $c$, arrows). Figure 9, Electron micrograph of the synapse established by side branch 14, displaying clearly defined round vesicles and a thick postsynaptic density. Figures 10-12, Electron micrographs showing three different synaptic regions of side branch 15 . The presynaptic terminal at all these synapses (arrows) is filled with a large number of synaptic vesicles (compare the synapses in ipsilateral LGN territory, Figs. 3-5). Figures 10 and 11 illustrate synapses onto immature dendritic elements; in Figure 11, the dendritic process is also postsynaptic to a non-HRP-labeled axon terminal (arrowhead). In Figure 12b, the bulbous nature of this type of postsynaptic appendage is clearly seen and contains microtubules $(m t)$ and actin-sized filaments $(f)$. Another common postsynaptic relationship is illustrated in Figure $12 a$, where the side branch courses for some distance parallel to a longitudinally orientated dendritic shaft $(D)$ containing characteristic bundles of microtubules $(m t)$. The side branch in this figure establishes two synaptic contacts from its en passant bouton (arrows in Figure $12 a$ and in the serial section of the same bouton, Figure $12 b$ ) and an unidentifiable contact (open triangle in the enlargement c). Figure 13 illustrates an unidentifiable contact (open triangle) at the very tip of side branch 18. Arrowhead indicates two vesicles. Figure 14 illustrates a synapse (arrow) established by the axon trunk close to side branch 18 . Scale bars: for Figs. $8 b, c$ and 9 , shown in Fig. 8, $0.2 \mu \mathrm{m}$; for Figs. 10 and 12b,c, shown in Fig. 10, $0.2 \mu \mathrm{m}$; Figs. 11 and $12 a, 0.5 \mu \mathrm{m}$; for Figs. 13 and 14, shown in Fig. 13, $0.2 \mu \mathrm{m}$. 


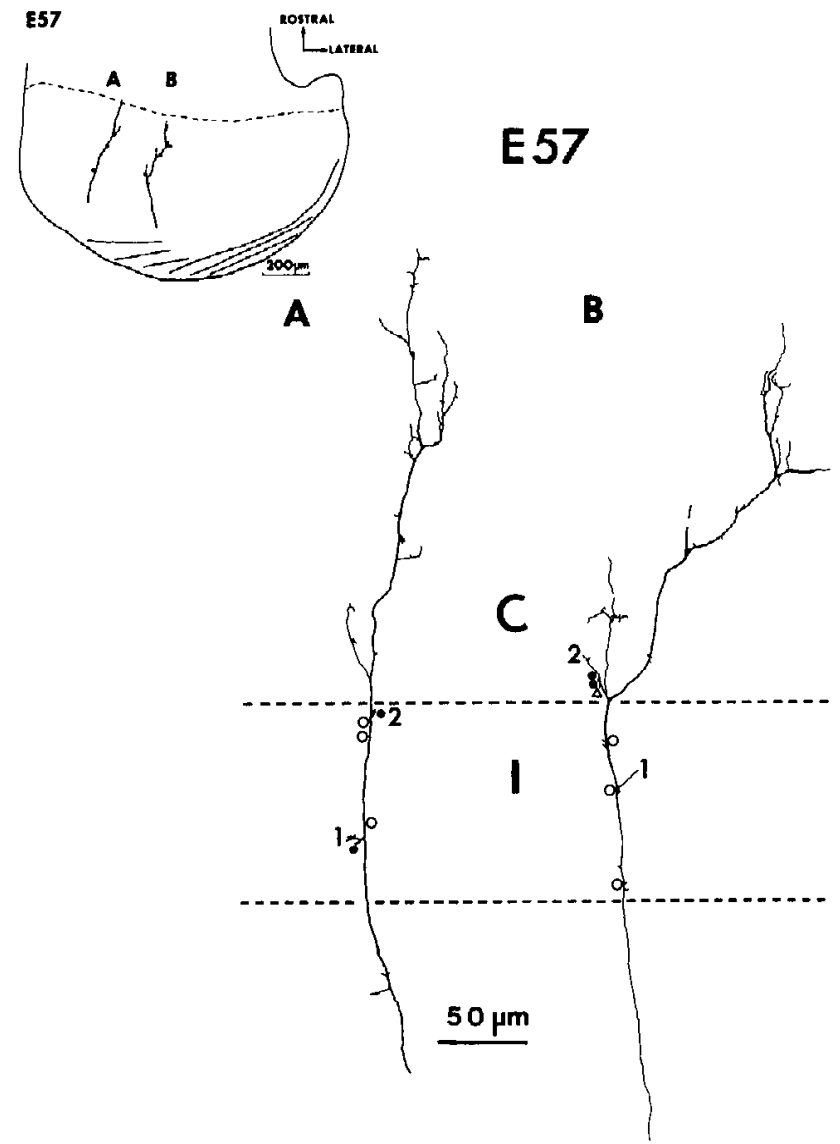

Figure 16. Summary drawing of the two E57 axons to illustrate identified contacts located within ipsilateral eye territory $(I)$ and within the border zone between ipsilateral and contralateral $(C)$ eye territory. At this age, very few synapses are present within ipsilateral cye territory, as compared with the large number established by the ES3 axon (Fig. 15). Symbols: solid circles, side branch synapses; open circles, trunk synapses; open triangles, unidentified contacts. Inset, Drawing of the labeled axons within a single resin-embedded, horizontal, Vibratome section of the LGN. The axons arise from close to the optic tract (bottom of inset) and form terminal arbors near the inner border of the nucleus (dashed line).

lateral eye axons can make synapses in territory belonging to the ipsilateral eye during development.

The results reported here extend those of a previous study of the hamster LGN by Campbell et al. (1984) showing that ganglion cell axons from both eyes can make inappropriately located synapses. However, in those previous experiments the entire retinogeniculate projection from one eye was labeled within the LGN by means of intraocular injection of HRP, thus making it impossible to relate the location of synapses to morphological features of individual axons. We could not tell, for example, whether the synapses made by one eye within territory belonging to the other eye were associated with terminal arbors, axons trunks, or the very characteristic side branches found transiently along the length of individual axons. Furthermore, we could not assess the frequency with which contralateral axons synapse in ipsilateral territory. In our present study, this difficulty has been overcome by the technique of completely filling individual axons with HRP, by directly relating the location of identified synapses to eye-specific territories, and by knowing the morphological identity of the structure bearing each synapse at the LM level. As shown in Figures 15 and 16, it is now possible to state that in the cat the majority of synapses made by an axon originating from one eye but located in territory belonging to the other are most likely to be made by side branches, while some can even be established directly by the main axon trunk.

By adulthood the side branches themselves disappear (Sretavan and Shatz, 1986; Fig. 1) and the preterminal portion of the axon becomes myelinated (Famiglietti and Peters, 1972; Bowling and Michael, 1980, 1984). In addition, neurons located in ipsilateral layer $\mathrm{A} 1$ do not receive direct monosynaptic excitation from retinal ganglion cells of the contralateral eye (Kato et al., 1971). Taken together with the present results, we can conclude that the synapses made in inappropriate territory are transient. Such synapses are likely to prove inexpensive to remove in view of our observations that they occupy only a small area of pre- and postsynaptic membrane and have few vesicles and only a modest postsynaptic density.

These results confirm the suggestion made by Sretavan and Shatz (1986) that side branches located in ipsilateral eye territory are presynaptic, and provide further insight into the nature and degree of transient synaptic interactions that may operate as axons from the two eyes segregate. The finding that synapses exist along the main axon trunk implies that considerably more sites of synaptic interaction are present than originally anticipated from the analysis of side branches in the previous LM study. In addition, as shown in Figure 15, we now know that a given side branch can form multiple synaptic contacts. However, synapses were not found on all of the side branches examined in serial sections at the EM level. At E53, five out of the eight side branches located in ipsilateral eye territory made one or more synaptic contacts; the three remaining side branches were very short ( $2 \mu \mathrm{m}$ or less) and, when examined in their entirety, revealed no clear evidence for the presence of a synapse. At E57, there are fewer and smaller side branches, and in presumptive ipsilateral eye territory, two out of three are presynaptic. The fact that synapses were not found on every side branch could be due to technical reasons including the loss of some serial sections, to the decision not to reconstruct all side branches in their entirety, or to the degradation of ultrastructure due to the slice preparation, fixation, or the presence of excessive HRP reaction product. However, it is equally likely that the synapses, like the side branches themselves, are dynamic structures that may be in the process of forming, or of being eliminated.

Comparison of synapses and postsynaptic elements within ipsilateral and contralateral regions and their relation to adult retinogeniculate synaptology

With the exception of vesicle number, features of synaptic morphology and the types of postsynaptic partners to labeled retinal terminals at E53 were similar within both ipsilateral and contralateral regions (Table 1). The length and width of postsynaptic densities were not significantly different for the two populations. Terminals in both sites synapsed onto variable-sized dendritic shafts and immature dendritic elements. However, significantly more vesicles were present within terminals located in the appropriate territory than within terminals in inappropriate territory. As discussed in the next section, we know that the synapses established in inappropriate territory are eliminated. Thus, this observation raises the possibility that the process of synapse elimination is not an all-or-none event but rather involves a gradual weakening of synaptic strength that is manifested at the ultrastructural level by a decrease in the number of synaptic vesicles.

In the adult cat, retinal ganglion cell terminal boutons in the LGN synapse mainly on dendritic appendages but can also be 
presynaptic to dendritic shafts (Peters and Palay, 1966; Szentágothai et al., 1966; Guillery, 1971; Mason et al., 1984; Rapisardi and Miles, 1984). For geniculate " $X$ "-cells it is thought that retinogeniculate boutons synapse only onto dendritic appendages, whereas geniculate "Y"-cells are postsynaptic mainly at dendritic shafts to retinogeniculate terminals (Wilson et al., 1984; Hamos et al., 1987). This applies at least to the more proximal dendritic regions. At E53, in both ipsilateral and contralateral regions, the axon we studied makes a similar number of contacts onto dendritic protrusions and onto dendritic shafts. However, we cannot say whether or not the axon is in fact an $\mathrm{X}$ or a $\mathrm{Y}$ axon for several reasons. First, there is no guarantee that the pattern of contacts seen at E53 will remain stable, even in contralateral eye territory. Second, retinal $X$ and $Y$ axons cannot be distinguished, physiologically or morphologically, until about 3 weeks postnatally (Sur et al., 1984; Sretavan and Shatz, 1986).

A single retinogeniculate axon at E53 encounters and synapses with many dendrites that, as revealed by the directionality of the microtubules, are oriented in various directions and therefore are likely to arise from several different LGN neurons. Little is known of the morphology of LGN neurons in the fetal cat, but preliminary studies using $1,1^{\prime}$-dioctodecyl-3,3,3',3'-tetramethylindocarbocyanine perchlorate labeling (Ghosh et al., 1990) suggest that many LGN neurons have dendritic trees more extensive than those described at postnatal day 3 by Mason (1983) in a Golgi study. These observations suggest that there could be a good deal of divergence between the E53 axon and its postsynaptic targets. Thus, this fetal axon may be less selective in its choice of postsynaptic partners than adult retinogeniculate axons, some of which seem to have great selectivity (Cleland et al., 1971; Hamos et al., 1987).

The adult retinogeniculate synaptic terminal in the cat can achieve a highly complex and stereotyped appearance. Presynaptic portions of the axon are RLP bouton-like (see Guillery, 1969; Mason and Robson, 1979); they form the central element in a set of synaptic relations (glomeruli) that are frequently encapsulated by glia (Szentágothai et al., 1966; Guillery, 1969). These mature synaptic features appear during postnatal life (Winfield and Powell, 1980; Mason, 1982; Kalil et al., 1986), and consistent with this point, the axons examined here at E53 or E57 showed none of the characteristic mature features. On the contrary, the majority of synapses werc remarkably simplc morphologically.

\section{Functional significance of transient synapses}

A major goal of the present study was to learn more about the role played by side branches in the segregation of ganglion cell axons from the two eyes into the eye-specific layers. The fact that side branches do make synapses is consistent with the suggestion made in the introductory remarks that segregation arises from a process of activity-driven competition between ganglion cell axons from the two eyes for postsynaptic territory on common LGN neurons (Shatz, 1988; Shatz and Stryker, 1988; Sretavan et al., 1988). Studies of other developing systems have suggested that this type of competition requires that the sets of competing inputs first form synapses with common target neurons, after which one of the sets is eliminated (for reviews, see Purves and Lichtman, 1980; Constantine-Paton and Reh, 1985; Schmidt and Tieman, 1985; Shatz, 1990a,b). However, while many previous studies have provided convincing physiological evidence that this is the case, the identity of the morphological substrate responsible for the synaptic convergence has been harder to come by because it is not often possible to identify conclusively which axons and processes will be eliminated and which will be retained. In the retinogeniculate system, it is possible to identify and examine morphological features that arc definitely transient - for example, the side branches arising from contralateral eye axons coursing through ipsilateral eye territory. The results of this study have shown that side branches and axon trunks are indeed synaptic sites, raising the possibility that similar ultrastructural substrates may participate in the interactions that occur between competing axons in other developing systems.

We have shown here that side branch synapses are present at E53 and E57, implying that at least at these ages individual LGN neurons located in ipsilateral eye territory receive convergent synaptic inputs from the terminal arbors of ipsilaterally projecting retinal ganglion cells and the side branches (or trunks) of contralaterally projecting axons. This anatomical pattern of synaptic input is likely to account for the known physiological convergence from the two eyes seen at these ages (Shatz and Kirkwood, 1984) and also implies that the side branch and/or trunk synapses are capable of functioning. In this regard, it is worth noting that physiologically, the synapses are very susceptible to fatigue, an observation consistent with our finding here of low numbers of synaptic vesicles. Our results also help to eliminate the possibility that the functional convergence of inputs from the two eyes onto common LGN neurons could be mediated by a disynaptic pathway within the LGN itself: for example, contralateral eye input to a neuron located in future ipsilateral eye territory might be relayed via an LGN neuron situated in future contralateral eye territory. The fact that side branches are synaptic sites indicates that LGN neurons in ipsilateral eye territory can receive direct monosynaptic inputs not only from the terminal arbors of ganglion cell axons originating in the ipsilateral eye, but also from axons belonging to the contralateral eye.

The important question remains of whether similar convergent synaptic interactions are present at the onset of segregation. Physiologically, in vitro studies have shown that as early as E42 (just prior to the onset of segregation) LGN neurons can be driven by electrical stimulation of both optic nerves (Shatz and Kirkwood, 1984). At similar ages, morphological studies have shown that side branches are present on axons even before the acquisition of definitive terminal arbors (Sretavan and Shatz, 1986; see also Fig. 1), and ultrastructural studies in progress indicate that at these very early times ganglion cells do form synaptic contacts within the LGN (Shatz et al., 1982). Thus, it is quite possible that the side branches and trunks of ganglion cell axons from both eyes establish synapses with common LGN neurons even at these early ages, and that through ensuing synaptically driven competitive interactions the two sets of axons carve out their appropriate eye-specific territories.

\section{References}

Bastiani MJ, Goodman CS (1984) Neuronal growth cones: specific interactions mediated by filopodial insertion and induction of coated vesicles. Proc Natl Acad Sci USA 81:1849-1853.

Bhide PG, Lieberman AR, Campbell G (1988) Dendritic invagination of developing optic tract axons in the hamster. Exp Brain Res 73: 519-522.

Blue MB, Parnavelas JG (1983) The formation and maturation of synapses in the visual cortex of the rat. I. Qualitative analysis. J Neurocytol 12:599-616.

Bowling DB, Michael CR (1980) Projection patterns of single physiologically characterized optic tract fibres in cat. Nature 286:899-902. Bowling DB, Michael CR (1984) Terminal patterns of single, physi- 
ologically characterized optic tract fibers in the cat's lateral geniculate nucleus. J Neurosci 4:198-216.

Callaway EM, Soha JM, Van Essen DC (1987) Competition favouring inactive over active motor neurons during synapse elimination. Nature 328:422-426.

Campbell G, Shatz CJ (1986) Synapses formed by individual retinogeniculate axons in inappropriate LGN territory during formation of eye-specific layers. Soc Neurosci Abstr 12:589.

Campbell G, So K-F, Lieberman AR (1984) Normal postnatal development of retinogeniculate axons and terminals and identification of inappropriately-located transient synapses. Electron microscope studies of horseradish peroxidase-labelled retinal axons in the hamster. Neuroscience 13:743-759.

Cleland BG, Dubin MW, Levick WR (1971) Sustained and transient neurones in the cat's retina and lateral geniculate nucleus. J Physiol (Lond) 217:473-496.

Constantine-Paton M, Reh TA (1985) Dynamic synaptic interactions during the formation of a retinotopic map. In: Neurobiology: molecular biological approaches to understanding neuronal function and development (O'Lague P, ed), pp 151-168. New York: Liss.

Constantine-Paton M, Cline HT, Debski E (1990) Patterned activity, synaptic convergence and the NMDA receptor in developing visual pathways. Ann Rev Neurosci 13:129-154.

Famiglietti EV Jr, Peters A (1972) The synaptic glomerulus and the intrinsic neuron in the dorsal lateral geniculate nucleus of the cat. $J$ Comp Neurol 144:285-334.

Gaunt WA (1971) Microreconstruction. London: Pitman.

Ghosh A, Dalva MB, Shatz CJ (1990) Prenatal development of LGN neuron dendrites during segregation of eye inputs. Soc Neurosci Abstr 16:1128

Guillery RW (1969) The organization of synaptic interconnections in the laminae of the dorsal lateral geniculate nucleus of the cat. Z Zellforsch $96: 1-38$

Guillery RW (1971) Patterns of synaptic interconnections in the cat and monkey dorsal lateral geniculate nucleus: a brief review. Vision Res [Suppl] 3:211-227.

Hamos JE, Van Horn S, Raczkowski D, Sherman SM (1987) Synaptic circuits involving an individual retinogeniculate axon in the cat. $J$ Comp Neurol 259:165-192.

Hinds JW, Hinds PL (1972) Reconstruction of dendritic growth cones in nconatal mouse olfactory bulb. J Neurocytol 1:169-187.

Kalil RE, Dubin M, Scott G, Stark LA (1986) Elimination of axon potentials blocks the structural development of retinogeniculate synapses. Nature 323:156-158.

Kato H, Yamamoto M, Nakahama H (1971) Intracellular recordings from the lateral geniculate neurones of cats. Jpn J Physiol 21:307323.

LeVay S, Hubel DH, Wiesel TN (1980) The development of ocular dominance columns in normal and visually deprived monkeys. $\mathbf{J}$ Comp Neurol 191:1-51.

Mason CA (1982) Development of terminal arbors of retino-geniculate axons in the kitten. II. Flectron microscopical observations. Neuroscience 7:561-582.

Mason CA (1983) Postnatal maturation of neurons in the cat's lateral geniculate nucleus. J Comp Neurol 217:458-469.

Mason CA, Robson JA (1979) Morphology of retino-geniculate axons in the cat. Neuroscience 4:79-97.

Mason CA, Guillery RW, Rosner MC (1984) Patterns of synaptic contact upon individually labeled large cells of the dorsal lateral geniculate nucleus of the cat. Neuroscience 11:319-329.

Peters A, Palay SL (1966) The morphology of laminae A and Al of the dorsal nucleus of the lateral geniculate body of the cat. J Anat $100: 451-486$

Peters A, Palay SL, Webster H de F (1976) The fine structure of the nervous system. Philadelphia: Saunders.

Purves D, Lichtman JW (1980) Elimination of synapses in the developing nervous system. Science 210:153-157.

Ramoa AS, Campbell G, Shatz CJ (1988) Dendritic growth and remodclling of cat retinal ganglion cells during fetal and postnatal development. J Neurosci 8:4239-4261.

Rapisardi SC, Miles TP (1984) Synaptology of the retinal terminals in the dorsal lateral geniculate nucleus of the cat. J Comp Neurol 223: 515-534.

Robson J, Mason CA (1979) The synaptic organization of terminals traced from individual labeled retino-geniculate axons in the cat. Neuroscience 4:99-111.

Schmidt JT, Tieman SB (1985) Eye-specific segregation of optic afferents in mammals, fish, and frogs: the role of activity. Cell $\mathrm{Mol}$ Neurobiol 5:5-34.

Shatz CJ (1983) The prenatal development of the cat's retinogeniculate pathway. J Neurosci 3:482-499.

Shatz CJ (1988) The role of function in the prenatal development of retinogeniculate connections. In: Cellular thalamic mechanisms (Bentivoglio M, Spreafico R, eds), pp 435-446. New York: Elsevier.

Shatz CJ (1990a) Competitive interactions between retinal ganglion cells during prenatal development. J Neurobiol 21:197-211.

Shatz CJ (1990b) Impulse activity and the patterning of connections during CNS development. Neuron 5:745-756.

Shatz CJ, Kirkwood PA (1984) Prenatal development of functional connections in the cal's retinogeniculate pathway. J Neurosci 4:13781397.

Shatz CJ, Sretavan DW (1986) Interactions between retinal ganglion cells during the development of the mammalian visual system. Annu Rev Neurosci 9:171-207

Shatz CJ, Stryker MP (1988) Formation of eye-specific layers in the lateral geniculate nucleus is blocked by tetrodotoxin. Science $242: 87-$ 89.

Shatz CJ, Kirkwond PA, Siegel MW (1982) Functional retinogeniculate synapses in fetal cats. Soc Neurosci Abstr 8:815.

Skoff RP, Hamburger V (1974) Fine structure of dendritic and axonal growth cones in embryonic chick spinal cord. J Comp Neurol 153 : 107-148.

So K-F, Campbell G, Lieberman AR (1990) Development of the mammalian retinogeniculate pathway: target finding, transient synapses and binocular segregation. J Exp Biol 153:85-104.

Sretavan DW, Shatz CJ (1984) Prenatal development of individual retinogeniculate axons during the period of segregation. Nature 308 845-848.

Sretavan DW, Shatz CJ (1986) Prenatal development of retinal ganglion cell axons: segregation into eye-specific layers within the cat's lateral geniculate nucleus. J Neurosci 6:234-251.

Sretavan DW, Shatz CJ (1987) Axon trajectories and pattern of terminal arborization during the prenatal development of the cat's retinogeniculate pathway. J Comp Neurol 255:386-400.

Sretavan DW, Shatz CJ, Stryker MP (1988) Modification of retinal ganglion cell axon morphology by prenatal infusion of tetrodotoxin. Nature 336:468-471.

Steward O, Falk PM (1985) Polyribosomes under developing spine synapses: growth specializations of dendrites at sites of synaptogenesis. J Neurosci Res 13:75-88.

Stryker MP, Harris WA (1986) Binocular impulse blockade prevents the formation of ocular dominance columns in cat visual cortex. J Neurosci 6:2117-2133.

Sur M, Weller RE, Sherman SM (1984) Development of X- and $Y$-cell retinogeniculate terminations in kittens. Nature 310:246-249.

Szentágothai J, Hámori J, Tömböl T (1966) Degeneration and electron microscope analysis of the synaptic glomeruli in the lateral geniculate body. Exp Brain Res 2:283-301.

Tosney KW, Landmesser LT (1985) Development of the major pathways for neurite outgrowth in the chick hindlimb. Dev Biol 109:193214.

Vaughn JE (1989) Fine structure of synaptogenesis in the vertebrate nervous system. Synapse 3:255-285.

Vaughn JE, Sims TJ (1978) Axonal growth cones and developing axon collaterals form synaptic junctions in embryonic mouse spinal cord. J Neurocytol 7:337-364.

Vaughn JE, Henrikson CK, Grieshaber JA (1974) A quantitative study of synapses on motor neuron dendritic growth cones in developing mouse spinal cord. J Cell Biol 60:664-672.

Westrum IE, Jones DH, Gray EG, Barron J (1980) Microtubules, dendritic spines and spine apparatuses. Cell Tissue Res 208:171-181.

Wilson JR, Friedlander MJ, Sherman SM (1984) Ultrastructural morphology of identified $X$ - and $Y$-cells in the cat's lateral geniculate nucleus. Proc R Soc Lond [Biol] 221:411-436.

Winfield DA, Powell TPS (1980) An electron microscopical study of the postnatal development of the lateral geniculate nucleus in the normal kitten and after eyelid suture. Proc R Soc Lond [Biol] 210: 197-210. 